\title{
MICROSTRUCTURAL, PHYSICAL AND MECHANICAL ANALYSIS OF RHA PORE MODIFIED POROUS ALUMINA WITH ALUMINUM AS REINFORCEMENT
}

\author{
Mohamad Aznan Mohamad Najib 1, *, Azmah Hanim Mohamed Ariff 1,3, Suraya \\ Mohamad Tahir ${ }^{1}$, Azizan As'arry ${ }^{1}$, and Norkhairunnisa Mazlan ${ }^{2}$ \\ ${ }^{1}$ Department of Mechanical and Manufacturing Engineering, Faculty of Engineering, Universiti Putra \\ Malaysia, Selangor, Malaysia, Tel: +603-89464387, e-mail: azmah@upm.edu.my \\ ${ }^{2}$ Department of Aerospace Engineering, Faculty of Engineering, Universiti Putra Malaysia, Selangor, \\ Malaysia \\ ${ }^{3}$ Research Center Advance Engineering Materials and Composites (AEMC), Faculty of Engineering, \\ Universiti Putra Malaysia, Selangor, Malaysia
}

Received Date: October 20, 2017; Revised Date: March 29, 2019; Acceptance Date: April 3, 2019

\begin{abstract}
Porous ceramics are being used in many industrial applications and processes that require extreme environment exposure due to its chemical inertness to corrosive medium and its ability to withstand high temperatures. Tailoring the porosity through pore modifier is one of the method available to ensure that the strength of ceramic is homogeneous. In order to improve the strength of the porous ceramic, the addition of aluminium powders was explored in this research. With the addition of agricultural waste source pore modifier and aluminium as reinforcement, the microstructure, linear shrinkage, porosity (open, closed and total), density, hardness and failure strength of this ceramic composite were examined. The ceramic composites were fabricated through powder metallurgy processing routes. Alumina, $\mathrm{Al}_{2} \mathrm{O}_{3}$ with the respective amounts of 0 to $10 \mathrm{wt} . \%$ (intervals of $10 \mathrm{wt} . \%$ ) of RHA and 0 to $10 \mathrm{wt} . \%$ (intervals of $2 \mathrm{wt} . \%$ ) of aluminum, $\mathrm{Al}$, were mixed homogeneously with $12 \mathrm{wt} . \%$ of sucrose solution. The mixtures were compacted and heat-treated for $1 \mathrm{~h}$ at each of the soaking temperatures of $200^{\circ} \mathrm{C}, 600^{\circ} \mathrm{C}$ and $1000^{\circ} \mathrm{C}$ followed by full sintering at $1550^{\circ} \mathrm{C}$ for $2 \mathrm{~h}$ in a furnace. The results have shown that open and total porosity increases with increasing amounts of RHA and aluminum. Meanwhile, the linear shrinkage, close porosity, density, hardness and failure strength was reduced. In this research, the strength was expected to increase with the addition of aluminum. However, due to the increasing percentage of the total porosity with the increased addition of aluminum, the samples behave inversely. Phase transformations to mullite $\left(3 \mathrm{Al}_{2} \mathrm{O}_{3} .2 \mathrm{SiO}_{2}\right)$ were seen in this research with the addition of RHA. This phase formation helps to increase the overall strength of the ceramic composites, showing that $10 \mathrm{wt} \%$ addition of RHA have a positive impact, not only as a medium to modify the pore formation, but it also has a positive effect on the strength property of the ceramic composite.
\end{abstract}

Keywords: Alumina, Ceramic matrix composite, Mechanical properties, Microstructure, Powder metallurgy, Sintering process

\section{Introduction}

The fabrication of composite materials by incorporating agro-industrial waste (such as coconut shell ash, fly ash (FA), rice husk ash (RHA), palm oil fuel ash (POFA), palm oil clinkers (POC), sugarcane bagasse, bamboo leaf and maize stalk ash) has attracted increasing interest among current researchers. The quantity of waste materials generated through industrial, mining and agricultural activities has increased due to the rapid growth of the world population and living standards. These waste materials are hard to dispose, thus 
increasing contamination in the environment with limited space for disposal [1]. The recycling of waste materials by converting them into green materials is the best solution to overcome this issue.

Research works involving the utilisation of agro-industrial waste have discovered that important elements exist in waste materials which can be used in a wide range of engineering applications. Almost all of the waste materials have a high percentage of silica, $\mathrm{SiO}_{2}$, content amongst their other constituents such as alumina, $\mathrm{Al}_{2} \mathrm{O}_{3}$, calcium oxide, $\mathrm{CaO}$, potassium oxide, $\mathrm{K}_{2} \mathrm{O}$ and others [2-4]. From previous studies, rice husk ash is one of the most silica-rich raw materials, containing about 90-98\% of crystalline silica (after burning) among other waste materials [5-7]. For that reason, the approach of using rice husk ash as a particulate in composite materials is a prime topic for many researchers.

In most metallic materials, the hardness is always lower than in ceramic materials, thus limiting its application. By embedding hard, stiff and low density rice husk ash, this can improve the hardness while reducing the overall density of the materials [8]. Meanwhile, a different approach has been tried involving incorporating rice husk ash in a ceramic material in order to fabricate a porous ceramic that can be used as a filter, catalyst support, thermal insulator, heat exchanger and etc. $[9,10]$.

Depending on the pore diameter, porous ceramics can be classified into three major groups: micro-porous $(\mathrm{d}<2 \mathrm{~nm})$, meso-porous $(50 \mathrm{~nm}>d>2 \mathrm{~nm})$ and macro-porous $(d>50$ $\mathrm{nm}$ ) with each of the pore diameters having its own specific applications [10]. The partial sintering process is one of the most conventional and frequently employed methods used to fabricate porous ceramic materials rather than sacrificial fugitives, replica templates and direct forming process [10]. Nevertheless, the use of only hard materials will increase the risk of brittle fracture, which takes place without any appreciable deformation by rapid crack propagation [11]. To overcome this intensive brittleness and the lack of reliability of the hard materials, metallic materials/metal phases were added [12].

In the present study, $\mathrm{Al}_{2} \mathrm{O}_{3} / \mathrm{Al}-\mathrm{RHA}$ composites with different compositions of RHA and aluminum were fabricated through powder metallurgy routes with the aid of sintering process. The effect of varying the composition of RHA (wt.\%) and Al (wt.\%) on the linear shrinkage, porosity (open, closed and total), density, hardness and failure strength values was evaluated. Moreover, some of the porous microstructural analysis was also included.

\section{Experimental Methodology}

Rice husk ash (RHA) supplied from a commercial source was ground using a high speed grinder and sieved to obtain particle sizes ranging from $125 \mu \mathrm{m}$ to $250 \mu \mathrm{m}$ using Retsch Analytical Sieve Shakers (Model: AS200). Rice husk ash was used as a pore forming agent in this study. Alumina, $\mathrm{Al}_{2} \mathrm{O}_{3}$, and aluminum, $\mathrm{Al}$, were homogenously mixed with RHA using a planetary micro mill (pulverisette 7) at a rotation speed of $250 \mathrm{rpm}$ for $30 \mathrm{mins}$ in a zirconium oxide $\left(94.20 \% \mathrm{ZrO}_{2}\right)$ grinding bowl. The ball to powder ratio was 10:1. $12 \mathrm{wt} . \%$ of sucrose solution (7 wt.\% sucrose on dry weight basis) was used as a binder and it also behaves as a pore former. The preparation of the binder was made by the dilution of solid sucrose with distilled water according to the mixture presented in Table 1.

The binder was mixed separately using an agate mortar with a pestle. The composition of RHA and Al were varied from 0 to $10 \mathrm{wt} \%$ (intervals of $10 \mathrm{wt} . \%$ ) and 0 to $10 \mathrm{wt} \%$ (intervals of $2 \mathrm{wt} \%$ ) respectively. The mixed powders were consolidated in a cylindrical die with a diameter of $20 \mathrm{~mm}$ using a Specac hydraulic press machine under 93.65 MPa pressure. 
Table 1. Mixture of the Sucrose Solution

\begin{tabular}{cc}
\hline Materials & $\begin{array}{c}\text { Weight } \\
\text { Percentage (wt.\%) }\end{array}$ \\
\hline Dry solid sucrose & 7 \\
Distilled water & 5 \\
\hline & Total $=\mathbf{1 2}$ \\
\hline
\end{tabular}

Magnesium stearate powder was used as a lubricant in order to reduce the friction between the powder and the surface of the die while obtaining good compaction finishes. Green compacted pellets were first dried in a Shelbab USA $1330 \mathrm{fx}$ forced air oven at $110^{\circ} \mathrm{C}$ for $24 \mathrm{~h}$ to remove the moisture and prevent cracking. Dried pellets were then made to undergo pre-sintering and sintering process as presented in Figure 1.

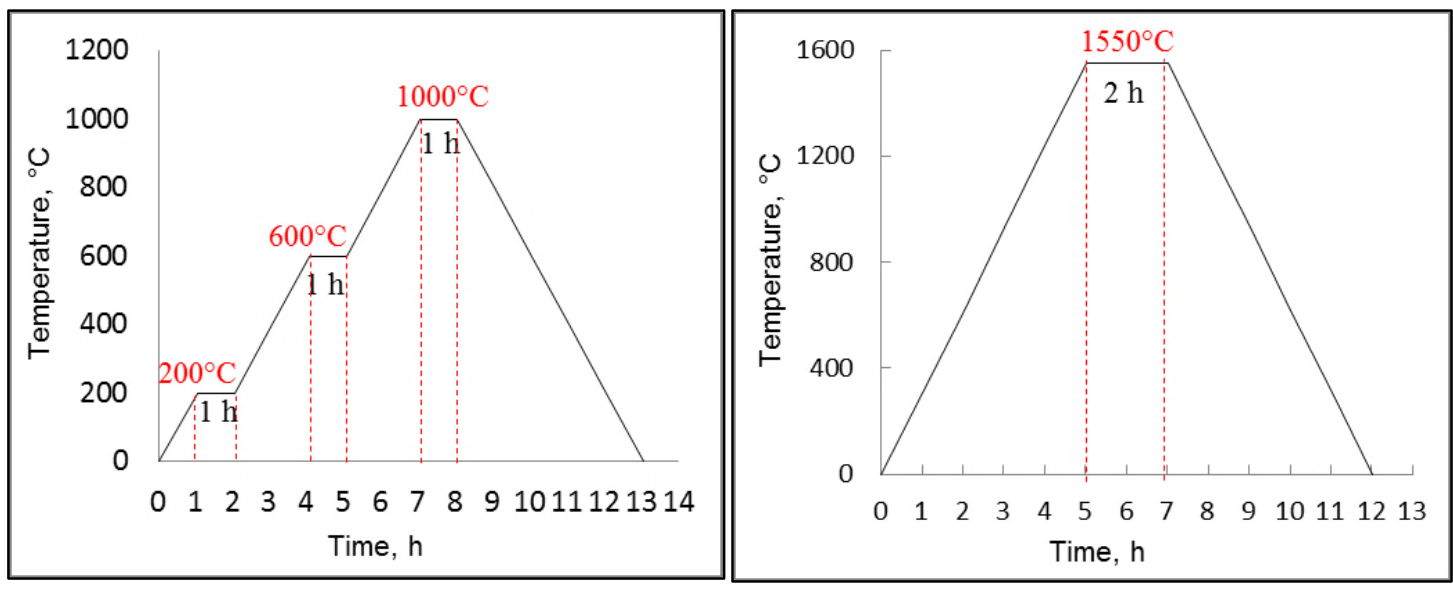

Figure 1. Sintering profile for the pre-sintering and sintering process

All the samples were characterised using ultra-high imaging resolution, FEI Nova NanoSEM 230 field emission scanning electron microscope (FESEM) with energy dispersive X-ray spectroscopy (EDX) in order to identify the elements and the particle size of the raw powders as well as the pore structure. Pore structure examination was also conducted using an optical microscope with an image analyser (OLYMPUS BX51RF) at 20x and 50x magnifications. For phase analysis, X-ray diffraction (XRD) was conducted using $\mathrm{Cu}_{\mathrm{k} \alpha}$ radiation with a 0.03 step size, position angle of $20^{\circ}-80^{\circ}$, and $40 \mathrm{~mA} / 40 \mathrm{kV}$ power sources. Peak shape analysis was performed using PANalytical X'Pert High Score software. Rietveld analysis was performed to determine the phase fractions.

In order to study the shrinkage of the sample after the sintering process, the sintering linear shrinkage was calculated by measuring the changes in the thickness of the green and sintered samples. The porosity (open, closed and total) and density of the respective sample were determined according to the Archimedes' principle using Equation 1,2 and 3 [13].

$$
\begin{aligned}
& \text { Density, } \rho\left(\mathrm{g} / \mathrm{cm}^{3}\right)=\frac{m_{1}}{m_{3}-m_{2}} \times \rho_{\mathrm{H}_{2} \mathrm{O}} \\
& \text { Open porosity, } P_{\text {Open }}(\%)=\frac{m_{3}-m_{1}}{m_{3}-m_{2}} \times 100 \\
& \text { Total porosity, } P_{\text {Total }}(\%)=\left(1-\frac{\rho}{\text { Theoretical density }}\right) \times 100
\end{aligned}
$$


The theoretical density was measured using the rule of mixtures. The mass of the sintered sample, $\mathrm{m}_{1}$, was measured directly after the sintering process. Then, the sample was hung using thin nylon wire $(0.32 \mathrm{~mm})$ and suspended in distilled water, $\mathrm{m}_{2}$. After soaking in distilled water, the sample was removed and excess water at the surfaces was lightly wiped off with a wet sponge. The mass of the sample after soaking in water, $\mathrm{m}_{3}$ was measured. This measurement was conducted using an analytical balance (Model: AS200) at room temperature. Hardness testing was conducted using a micro Vickers indentation tester (401MVD) at $100 \mathrm{gf}$ applied load for $20 \mathrm{~s}$ dwell times. The sample was first ground using $\mathrm{SiC}$ paper and polished using a polishing cloth with an alumina suspension $(0.05 \mu \mathrm{m})$ to provide a high surface quality for accuracy and repeatability of the test results. The failure strength (indirect tensile strength) was tested using a universal testing machine (UTM)Instron 3382 with a maximum load capacity of $100 \mathrm{kN}$ at room temperature. The samples were compressed diametrically between two flat platens with a crosshead rate of 0.50 $\mathrm{mm} / \mathrm{min}$. An average of five samples was used to obtain the value of the sintering linear shrinkage, porosity (open, closed and total), density, hardness and failure strength.

\section{Results and Discussion}

\section{Characterisation of Powders}

Figure 2a-c illustrates the FESEM images for the as received powders of alumina, aluminum and grounded rice husk ash (RHA). From this assessment, alumina and aluminum have a round to spherical shape with an average particle size that varies from 127.15 to $176.01 \mathrm{~nm}$ and 52.03 to $86.77 \mathrm{~nm}$ respectively. For the RHA, it has a cellular structure and an irregular shape consisting of multilayered, angular and microporous surfaces. RHA has also been examined by Chindaprasirt et al. [14] and Habeed et al. [15], and they have revealed a similar structure.
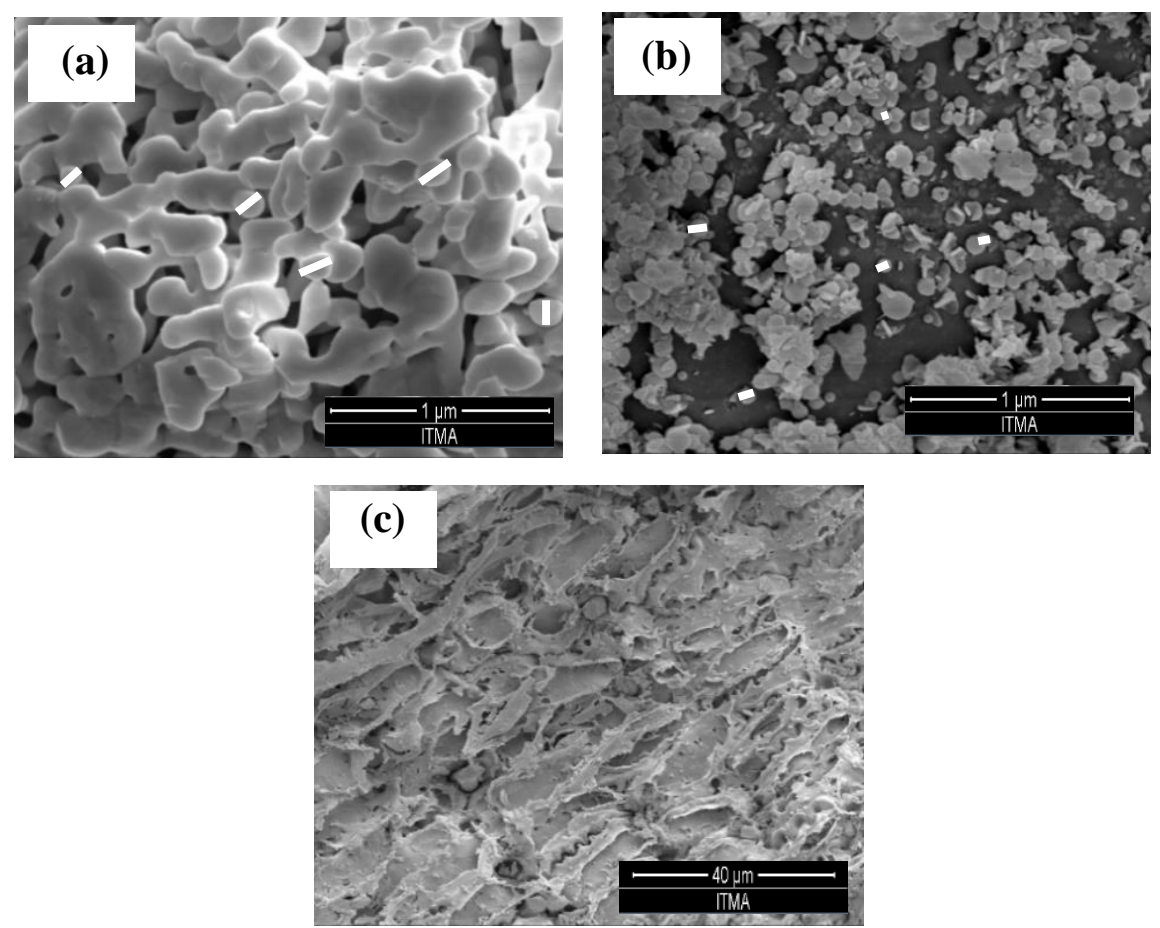

Figure 2. Particle size measurements of as-received powders (a) alumina, $\mathrm{Al}_{2} \mathrm{O}_{3}$, (b) aluminum, $\mathrm{Al}$ and (c) ground rice husk ash (RHA) 
The purity of the as received alumina powder was approximately up to $99.90 \%$. Figure $3 \mathrm{a}$ showed the elements of aluminum $(\mathrm{Al})$ and oxygen $(\mathrm{O})$ exist within the alumina which are the basic elements of alumina $\left(\mathrm{Al}_{2} \mathrm{O}_{3}\right)$ [16]. Hence, it is confirmed that there is no contamination in the alumina powder. Meanwhile, the element carbon (C) was detected in the aluminum powder (Figure $3 \mathrm{~b}$ ). This is due to the penetration of the high energy electron beam into the carbon tape which is used to attach the powder to the sample holder. On the other hand, the element oxygen is also detected in the aluminum powder. As mentioned by Eric, aluminum is a reactive material which will react spontaneously with moisture and/or air and tends to form oxide materials [17]. In other words, there is an oxidation process. For RHA (Figure 3c), the elements that exist are silicon ( $\mathrm{Si})$, calcium $(\mathrm{Ca})$, magnesium $(\mathrm{Mg})$, potassium $(\mathrm{K})$ and oxygen, which are common elements that exist in RHA as reported by most researchers $[1,2,6,18-20]$.
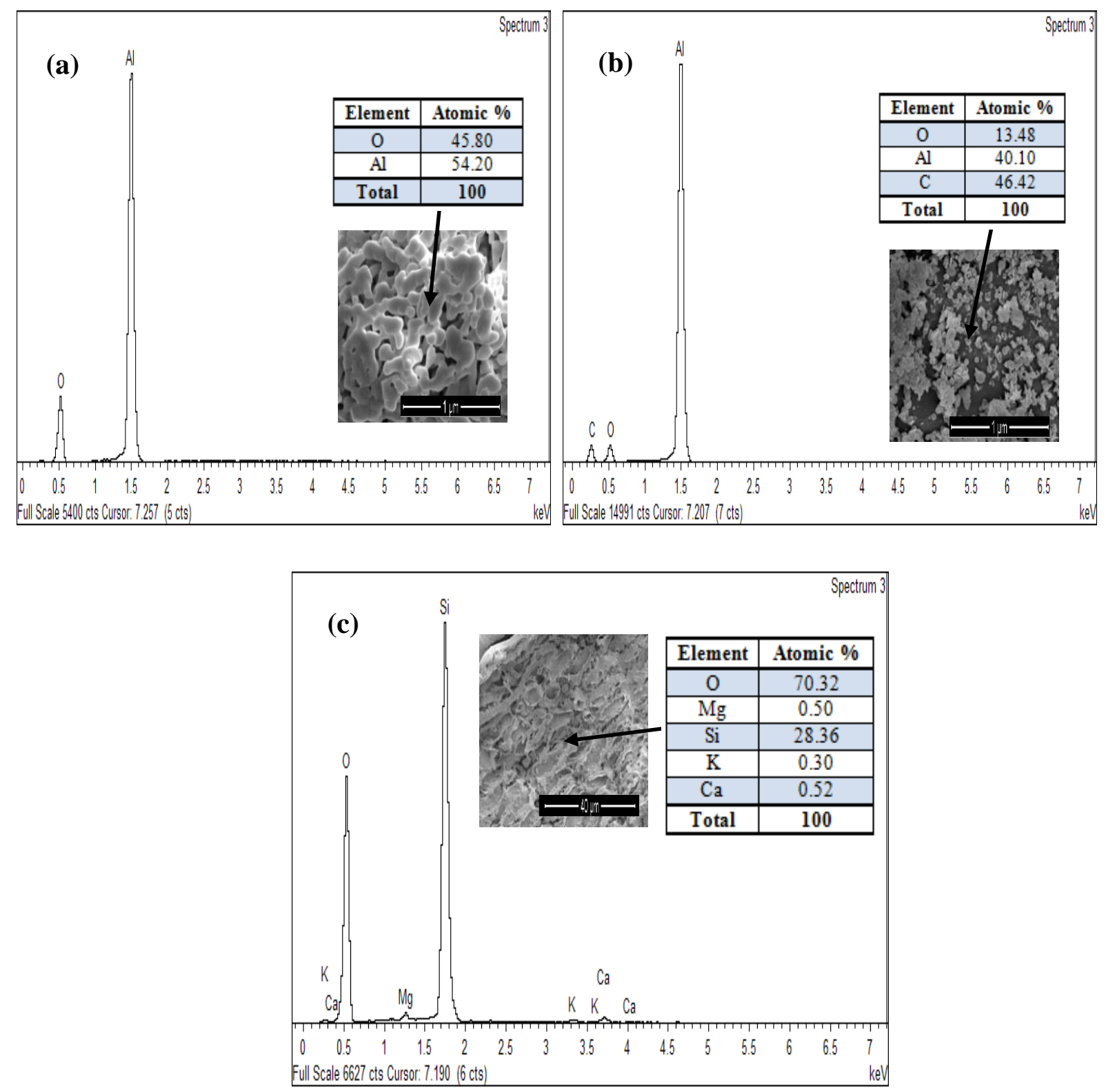

Figure 3. Elemental analysis with energy spectrum peak for as-received powders: (a) alumina, $\mathrm{Al}_{2} \mathrm{O}_{3}$, (b) aluminum, $\mathrm{Al}$ and (c) ground rice husk ash (RHA) 


\section{Characterisation of Sintered Pellets}

X-Ray Diffraction (XRD) analysis from Figure 4a-b shows two different samples of the sintered matrix alumina for $\mathrm{Al}_{2} \mathrm{O}_{3}$-sucrose solution and $\mathrm{Al}_{2} \mathrm{O}_{3} / \mathrm{Al}-\mathrm{RHA}$ system. From this interpretation, the incorporation with RHA and aluminum will result in slight changes from aluminum oxide-alpha $\left(\alpha-\mathrm{Al}_{2} \mathrm{O}_{3}\right)$ phases to mullite $\left(3 \mathrm{Al}_{2} \mathrm{O}_{3} \cdot 2 \mathrm{SiO}_{2}\right)$ phases due to the active reaction of the alumina with the $\mathrm{SiO}_{2}$ derived from RHA. It is about $27.60 \%$ of $\alpha-$ $\mathrm{Al}_{2} \mathrm{O}_{3}$ phases was transformed to mullite phases. Aluminum with $\left(\begin{array}{lll}0 & 2 & 2\end{array}\right)$ orientation was observed at $65.24^{\circ}$ (Figure $4 \mathrm{~b}$ ). The lattice constants were $\mathrm{a}(=\mathrm{b})=4.76 \AA, \mathrm{c}=13.00 \AA$ for $\alpha$ $\mathrm{Al}_{2} \mathrm{O}_{3}$ where the $\mathrm{O}$ and $\mathrm{Al}$ were positioned at $18 \mathrm{e}$ and $12 \mathrm{c}$. For $\alpha-\mathrm{Al}_{2} \mathrm{O}_{3}$ phase, the number of repetitions (sof) for both $\mathrm{O}$ and $\mathrm{Al}$ was only 1.00. For $3 \mathrm{Al}_{2} \mathrm{O}_{3} .2 \mathrm{SiO}_{2}$ and $\mathrm{Al}$, details of the refinement analysis are presented in Table 2. Conversion of $\alpha-\mathrm{Al}_{2} \mathrm{O}_{3}$ to mullite phases may affect the behaviour of the samples as the properties of mullite is different from $\alpha-\mathrm{Al}_{2} \mathrm{O}_{3}$. This will be discussed in the next section.

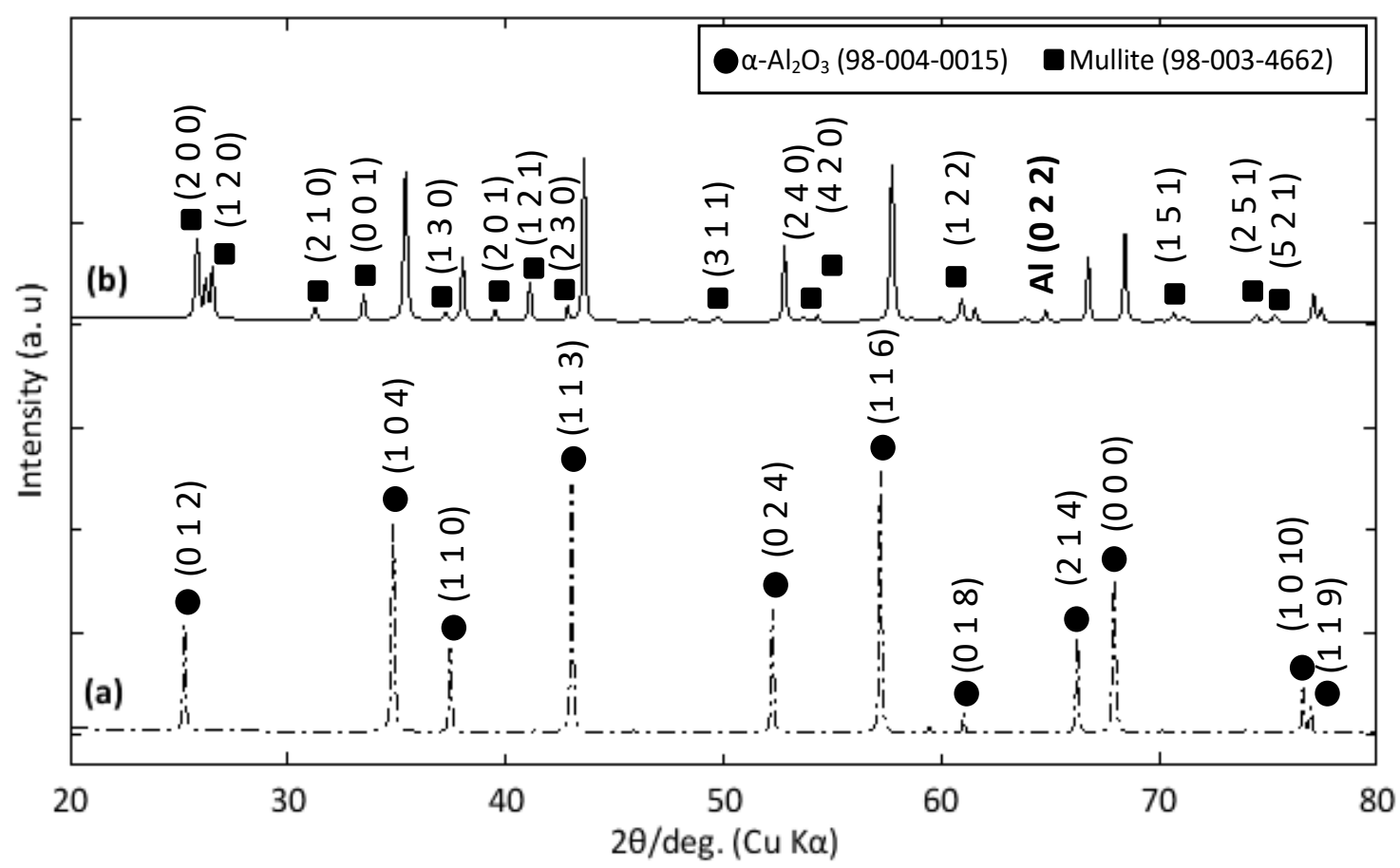

Figure 4. X-ray diffraction (XRD) patterns with phases identification and miller indices of sintered pellets: (a) $\mathrm{Al}_{2} \mathrm{O}_{3}+\mathrm{SS}$ and (b) $\mathrm{Al}_{2} \mathrm{O}_{3}+\mathrm{RHA}+\mathrm{Al}+\mathrm{SS}$. $* \mathrm{Al}_{2} \mathrm{O}_{3}=$ alumina, $\mathrm{RHA}=$ rice husk ash, $A l=$ aluminum, $S S=$ sucrose solution

\section{Mechanical Properties of Sintered Pellets}

Sintering linear shrinkage declines with the addition of RHA and aluminum. From Figure 5, the prominent linear shrinkage was shown for alumina without either RHA or aluminum, having the value of $17.42 \pm 0.47 \%$. $\mathrm{Al}_{2} \mathrm{O}_{3}$ become denser after sintering as a result of higher volumetric changes [12]. This value kept decreasing to $12.11 \pm 0.19 \%$ up to $10 \mathrm{wt} . \%$ of $\mathrm{Al}$ for $0 \mathrm{wt} . \%$ of RHA. A similar trend was seen for $10 \mathrm{wt} . \%$ addition of RHA (decreased from $6.44 \pm 0.15 \%$ to $2.38 \pm 0.62 \%$ ). This can be justified due to the increasing total volume fraction of aluminum which has a higher coefficient of thermal expansion (24.80 $\left.\alpha \times 10^{-6} \mathrm{~K}^{-1}\right)$ than alumina $\left(6.20 \alpha \times 10^{-6} \mathrm{~K}^{-1}\right)$, which will lead to the expansion of the grains and hence a larger sized sample [21-23]. 


$\begin{array}{cc}\mathrm{R}_{\mathrm{p}}(\%) & 12.33 \\ \mathrm{R}_{\mathrm{wp}}(\%) & 15.24 \\ \mathrm{GoF} & 6.01\end{array}$

\begin{tabular}{|c|c|c|c|c|c|}
\hline \multicolumn{2}{|c|}{$\begin{array}{l}\text { Aluminum oxide-alpha, } \\
\qquad \alpha-\mathrm{Al}_{2} \mathrm{O}_{3}\end{array}$} & \multicolumn{2}{|c|}{$\begin{array}{c}\text { Mullite, } \\
\mathbf{3 A l}_{2} \mathrm{O}_{3} \cdot \mathbf{2 \mathrm { SiO } _ { 2 }}\end{array}$} & \multicolumn{2}{|c|}{$\begin{array}{c}\text { Aluminum, } \\
\text { Al }\end{array}$} \\
\hline$a(=b)[\AA]$ & 4.76 & $\mathrm{a}[\AA]$ & 7.55 & $\mathrm{a}(=\mathrm{b}=\mathrm{c})[\AA]$ & 4.05 \\
\hline & & $\mathrm{b}[\AA]$ & 7.69 & & \\
\hline $\mathrm{c}[\AA ̊]$ & 13.00 & c $[\AA]$ & 2.89 & & \\
\hline Oxygen site & $18 \mathrm{e}$ & Oxygen site & $\begin{array}{l}\mathrm{O} 1(=\mathrm{O} 4)=4 \mathrm{~g} \\
\mathrm{O} 2=2 \mathrm{a}, \mathrm{O} 3=4 \mathrm{~h}\end{array}$ & $\begin{array}{l}\text { Aluminum } \\
\text { site }\end{array}$ & $4 a$ \\
\hline $\mathrm{x}$ & 0.31 & $\mathrm{x}$ & $\begin{array}{l}\mathrm{O} 1=0.45, \mathrm{O} 2=0.00 \\
\mathrm{O} 3=0.13, \mathrm{O} 4=0.35\end{array}$ & $x(=y=z)$ & 0.00 \\
\hline $\mathrm{y}$ & 0.00 & $\mathrm{y}$ & $\begin{array}{l}\mathrm{O} 1=0.38, \mathrm{O} 2=0.00 \\
\mathrm{O} 3=0.27, \mathrm{O} 4=0.07\end{array}$ & & \\
\hline $\mathrm{z}$ & 0.25 & $\mathrm{z}$ & $\begin{array}{l}\mathrm{O} 1(=\mathrm{O} 2=\mathrm{O} 4)= \\
0.00 \\
\mathrm{O} 3=0.50\end{array}$ & & \\
\hline sof & 1.00 & sof & $\begin{array}{l}\mathrm{O} 1=0.11, \mathrm{O} 2=0.66 \\
\mathrm{O} 3(=\mathrm{O} 4)=1.00\end{array}$ & sof & 1.00 \\
\hline $\mathrm{B}_{\text {iso }}$ & 1.53 & $\mathrm{~B}_{\text {iso }}$ & $\begin{array}{l}\mathrm{O} 1(=\mathrm{O} 3=\mathrm{O} 4)= \\
4.40 \\
\mathrm{O} 2=5.50\end{array}$ & $\mathrm{~B}_{\text {iso }}$ & 0.50 \\
\hline $\begin{array}{l}\text { Aluminum } \\
\text { site }\end{array}$ & $12 \mathrm{c}$ & $\begin{array}{l}\text { Aluminum } \\
\text { site }\end{array}$ & $\begin{array}{l}\mathrm{Al} 1(=\mathrm{Al} 2)=4 \mathrm{~g} \\
\mathrm{Al} 3=2 \mathrm{~d}\end{array}$ & & \\
\hline $\mathrm{x}(=\mathrm{y})$ & 0.00 & $\mathrm{x}$ & $\begin{array}{l}\mathrm{A} 11=0.28, \mathrm{Al} 2=0.15 \\
\mathrm{Al} 3=0.00\end{array}$ & & \\
\hline & & $\mathrm{y}$ & $\begin{array}{l}\mathrm{A} 11=0.28, \mathrm{Al} 2=0.16 \\
\mathrm{Al} 3=0.50\end{array}$ & & \\
\hline $\mathrm{z}$ & 0.15 & $\mathrm{z}$ & $\begin{array}{l}\mathrm{Al} 1(=\mathrm{A} 12)=0.00 \\
\mathrm{Al} 3=0.50\end{array}$ & & \\
\hline sof & 1.00 & sof & $\begin{array}{l}\mathrm{A} 11=0.11, \mathrm{Al} 2=0.50 \\
\mathrm{Al} 3=1.00\end{array}$ & & \\
\hline $\mathrm{B}_{\text {iso }}$ & 1.68 & $\mathrm{~B}_{\text {iso }}$ & $\begin{array}{l}\mathrm{A} 11=1.50, \mathrm{Al} 2=3.70 \\
\mathrm{Al} 3=3.10\end{array}$ & & \\
\hline & & Silicon site & $4 \mathrm{~g}$ & & \\
\hline & & $\mathrm{x}$ & 0.15 & & \\
\hline & & $\mathrm{y}$ & 0.16 & & \\
\hline & & $\mathrm{Z}$ & 0.00 & & \\
\hline & & sof & 0.39 & & \\
\hline & & $\mathrm{B}_{\text {iso }}$ & 3.70 & & \\
\hline
\end{tabular}

The effect for the sintering linear shrinkage with the addition of aluminum shows minimum changes of $5.31 \pm 0.28 \%$ and $4.06 \pm 0.47 \%$ reduction for both $0 \mathrm{wt} \%$ and $10 \mathrm{wt} \%$ of RHA as compared to the addition of RHA, which having the reduction changes range from $9.73 \pm 0.43 \%$ to $11.07 \pm 0.17 \%$ for $0 \mathrm{wt} \%$ to $10 \mathrm{wt} \%$ of aluminum. The presence of RHA will obstruct densification and pore collapse due to its hard properties [24, 25], and also the existence of the mullite phase as detected in the XRD [26]. 


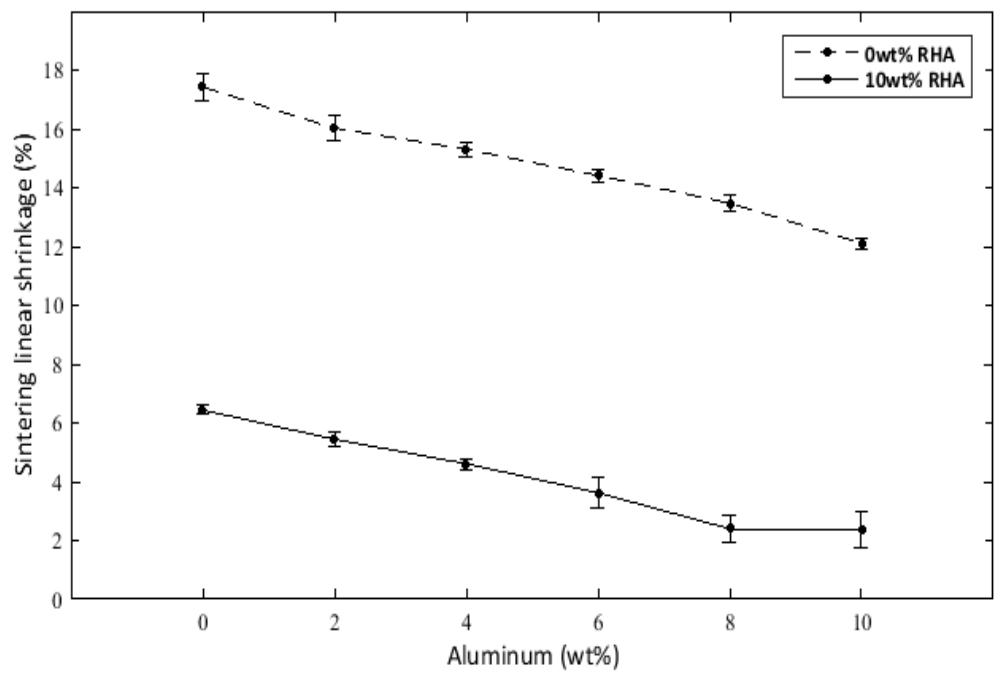

Figure 5. Reduction in linear shrinkage with the addition of RHA and aluminum

The sum of open (an accessible pore channel) and closed porosity is referred to as the total porosity. For $0 \mathrm{wt} . \%$ RHA, it showed that the open porosity increased with additional amounts of aluminum (Figure 6a). It was increased from $10.82 \pm 0.36 \%$ to $19.46 \pm 0.77 \%$ (increment of $8.64 \pm 0.41 \%$ ) up to $8 \mathrm{wt} . \% \mathrm{Al}$ and decreased to $19.23 \pm 0.53 \%$ (decrement of $0.24 \pm 0.23 \%$ ) at $10 \mathrm{wt} . \%$ Al. Similar trend were obtained for the sample having $10 \mathrm{wt}$.\% RHA (Figure 6a). The results for closed porosity was opposite from the open porosity. As showed in Figure $6 \mathrm{~b}$, it was observed that the closed porosity reduced when the aluminum content increased. The values were reduced from $22.75 \pm 1.11 \%$ to $15.91 \pm 1.53 \%$ (decrement of $6.84 \pm 0.42 \%$ ) and $16.31 \pm 0.33$ to $7.44 \pm 0.47 \%$ (decrement of $8.87 \pm 0.14 \%$ ) for $0 \mathrm{wt} . \%$ and $10 \mathrm{wt} . \%$ RHA, respectively. For this reason, as higher amounts of aluminum were added, there was an increase in the total volume fraction of aluminum. Thus, this may produce a higher tendency for the molten aluminum to be entrapped within the sample.

In overall, it can be said that the total porosity increased with the addition of RHA and aluminum (Figure 6c). Embedded with $10 \mathrm{wt} . \%$ RHA attributed to the increase in total porosity with increment values ranging between $12.03 \pm 1.14 \%$ and $15.23 \pm 0.37 \%$. This occurrence was due to the burning out of the organic materials/elements from RHA, which lead to the formation of pores. Figure 7a illustrates images of the formation of long, irregular and different pore shapes and sizes. The non-uniformity of pore structure and size was mainly due to the nature of the physical appearance of RHA as discussed in the previous section. With addition of aluminum, the total porosity increased from $33.56 \pm 1.01 \%$ to $36.55 \pm 0.77 \%$ (increment of $2.99 \pm 0.34 \%$ ) up to $8 \mathrm{wt} . \% \mathrm{Al}$ and decreased to $35.14 \pm 1.28 \%$ (decrement of $1.41 \pm 0.61 \%$ ) at $10 \mathrm{wt} . \% \mathrm{Al}$ for $0 \mathrm{wt} . \%$ RHA. Similar trend was obtained for 10 wt.\% RHA with increasing the aluminum content (Figure 6c). The increase in total porosity with additional amounts of aluminum can be understood through the theoretical melting temperature of aluminum. When sintered above $660.30^{\circ} \mathrm{C}$ [11], the aluminum will melt and it changes to molten aluminum. There are possibilities of the molten aluminum to immersed within the interfaces of the sintered alumina body and flowing out from the sample, thus, leaving the pores. The microscopic images in Figure $7 \mathrm{~b}$ show the porosity created by the aluminum particulates within the sample. Thus, this explained the reason how the addition of aluminum leads to the formation of pores and increased porosity. However, the increment is very small $(\leq 4.35 \%)$. Figure $7 \mathrm{c}$ emphasizes the perfect and poor interfacial bonding between alumina and aluminum within the sample. From these results, the 
relationship of the total porosity to the open and closed porosity can be described as following:

i. The closed porosity will dominate as the fractional porosity is lower.

ii. The open porosity will increase as the fractional porosity increase.
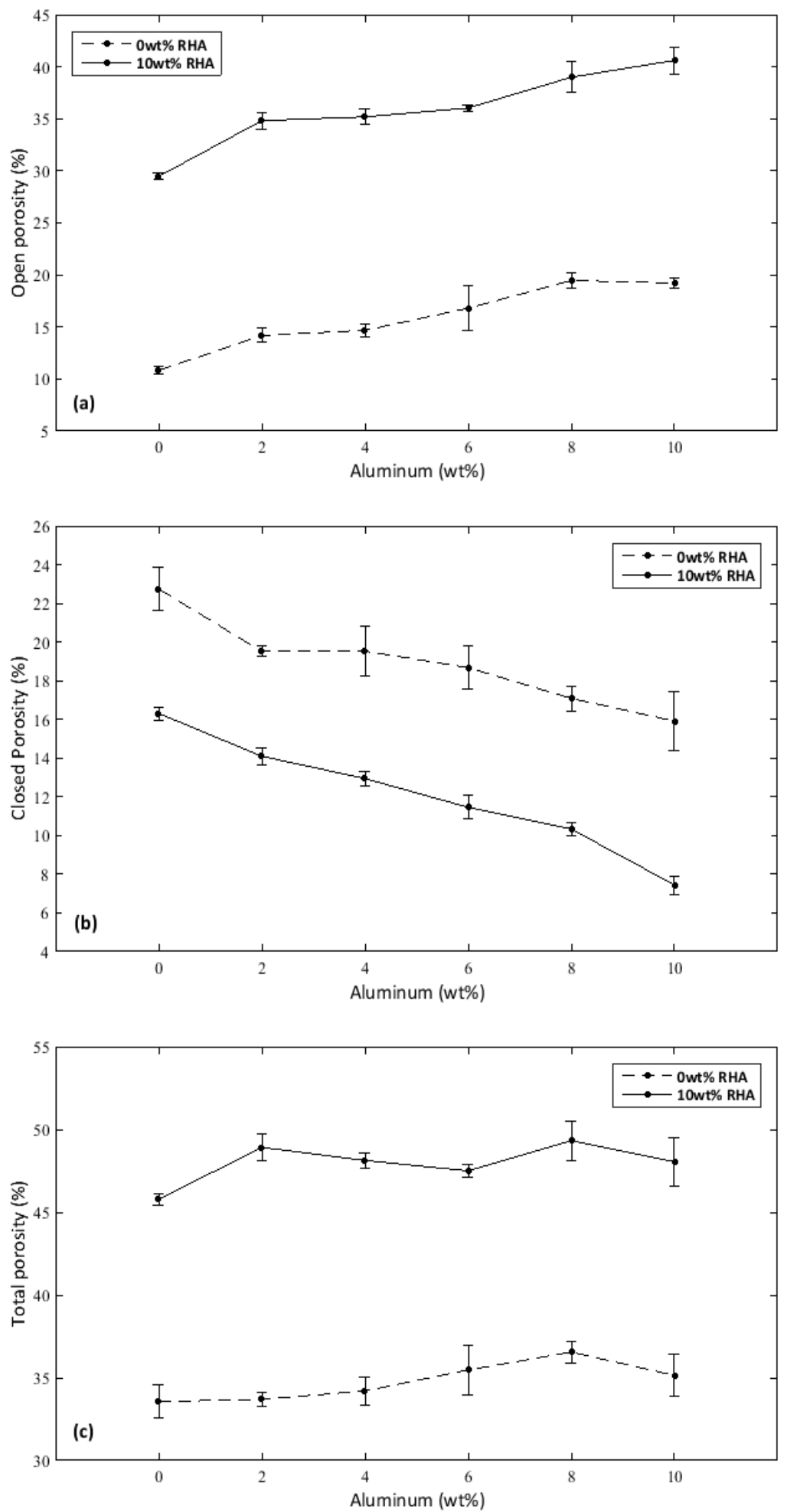

Figure 6. Variation of (a) open, (b) closed and (c) total porosity of the sintered alumina with the addition of RHA and aluminum 

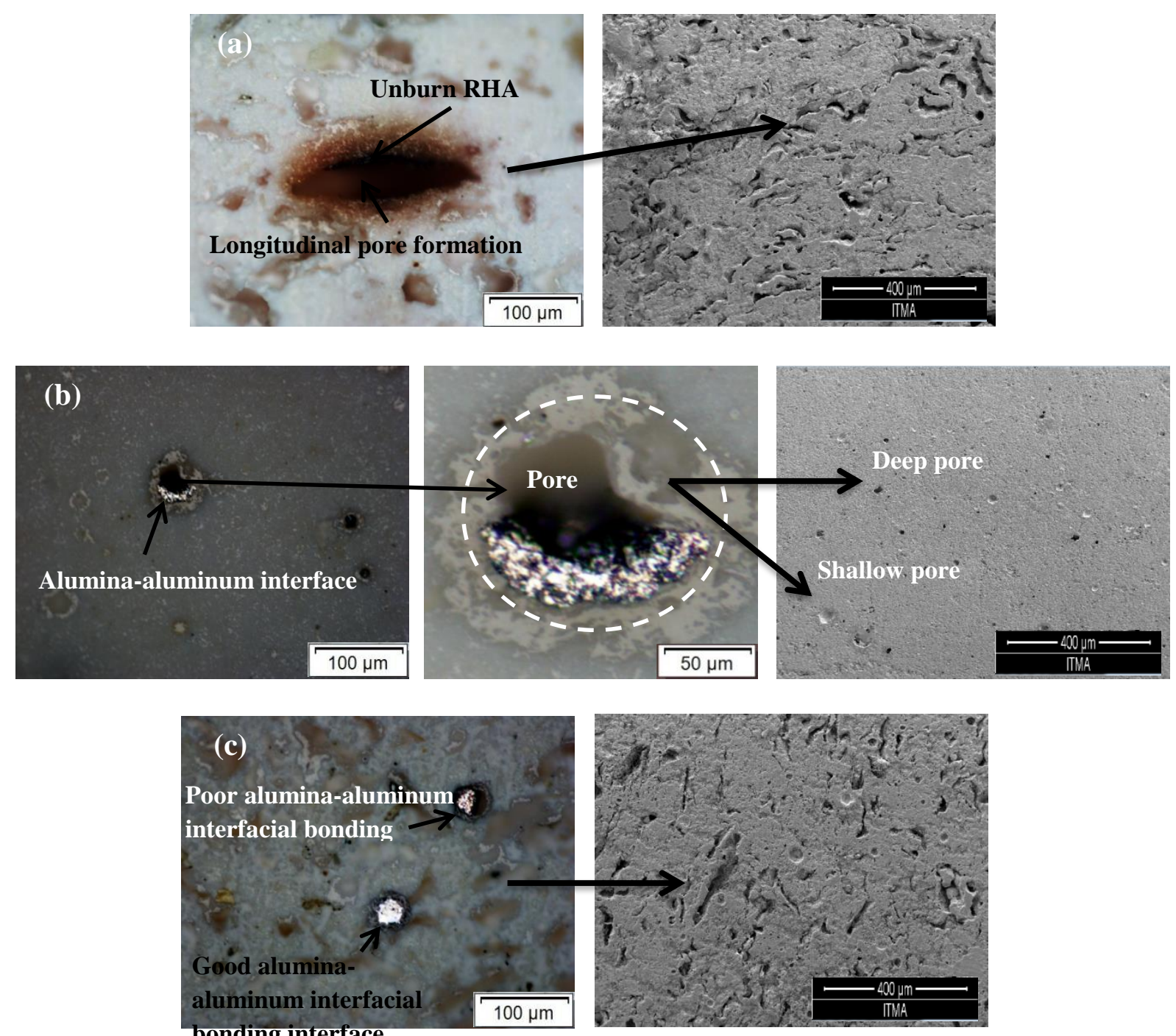

Figure 7. OM and FESEM images of (a) irregular pores structure created from RHA (b) deep and shallow pores formation created from aluminum and (c) good and poor interfacial reaction between the alumina matrix and aluminum

The density without RHA showed a higher density value (between $1.93 \pm 0.02$ $\mathrm{gcm}^{-3}$ and $2.08 \pm 0.03 \mathrm{gcm}^{-3}$ ) compared to the addition of $10 \mathrm{wt} . \%$ RHA (between $1.41 \pm 0.03$ $\mathrm{gcm}^{-3}$ and $1.55 \pm 0.01 \mathrm{gcm}^{-3}$ ) as shown in Figure 8. The reduction values were in the range between $0.51 \pm 0.04 \mathrm{gcm}^{-3}$ and $0.61 \pm 0.01 \mathrm{gcm}^{-3}$. The highest density measured was $2.08 \pm 0.03$ $\mathrm{gcm}^{-3}$, which is without particulates both RHA and aluminum. This is reasonable as a higher linear shrinkage occurs and the lower value of total porosity for this samples [4]. Density strictly depends on the sintering linear shrinkage and total porosity. The density is always being linearly proportional to the sintering linear shrinkage and inversely proportional to total porosity [9]. For both $0 \mathrm{wt} . \%$ and $10 \mathrm{wt} . \%$ RHA, the density values kept decreasing up to 8 wt. $\% \mathrm{Al}\left(2.08 \pm 0.03 \mathrm{gcm}^{-3}\right.$ to $1.93 \pm 0.02 \mathrm{gcm}^{-3}$ for 0 wt. $\%$ RHA and $1.55 \pm 0.01 \mathrm{gcm}^{-3}$ to $1.41 \pm 0.03 \mathrm{gcm}^{-3}$ for $10 \mathrm{wt} . \%$ RHA) due to increase in total porosity. However, the density started recovering again at $10 \mathrm{wt} . \% \mathrm{Al}$ (increased to $1.96 \pm 0.04 \mathrm{gcm}^{-3}$ and $1.44 \pm 0.04 \mathrm{gcm}^{-3}$ for $0 \mathrm{wt} . \%$ and $10 \mathrm{wt} . \%$ RHA, respectively). These increments were related to the reduction in total porosity due to the elimination of pores [27]. A lowering of the density value also was attributed to the addition of low density RHA $\left(1.80 \mathrm{~g} / \mathrm{cm}^{3}\right)$ [28-30] and aluminum $(2.70$ $\mathrm{g} / \mathrm{cm}^{3}$ ) [11]. 


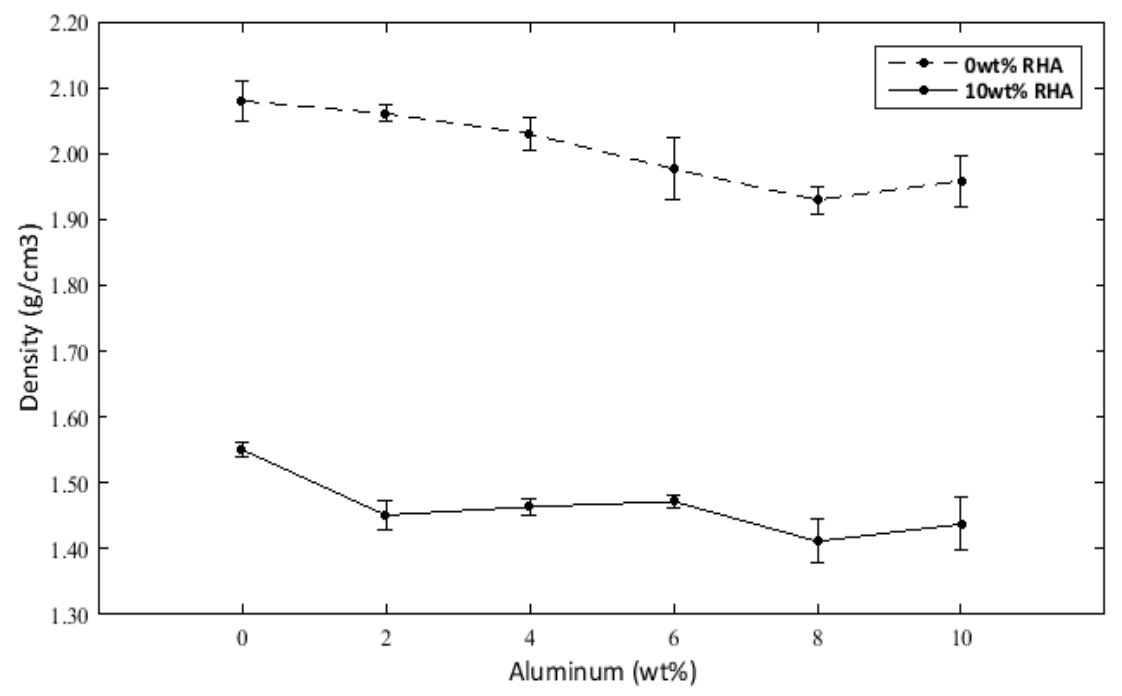

Figure 8. Reduction in density with the variation amounts of RHA and aluminum

The hardness of the sintered samples reduces with the increasing content of RHA and aluminum. From Figure 9, the hardness value decreases from 373.12 $\pm 22.20 \mathrm{HV}$ to the minimum value of $75.78 \pm 6.11 \mathrm{HV}$ with increasing amounts of RHA up to $10 \mathrm{wt} \%$. Due to the role of RHA as a pore forming agent, most of the organic materials/elements were removed during the sintering treatment, leaving more pores inside the material (reduced resistance to failure) and thus reducing the hardness. Meanwhile, with increasing amounts of aluminum, this also leads to a reduction in hardness. The values reduced from $373.12 \pm 22.20 \mathrm{HV}$ to $176.12 \pm 5.99 \mathrm{HV}$ (decrement of $197.00 \pm 16.21 \mathrm{HV}$ ) without RHA and from $75.78 \pm 6.11 \mathrm{HV}$ to $36.00 \pm 9.28 \mathrm{HV}$ (decrement of $39.78 \pm 3.17 \mathrm{HV}$ ) with 10 wt. $\%$ RHA, respectively.

The reduction of hardness was attributed to the presence of the mullite phases, which has lower properties than $\alpha-\mathrm{Al}_{2} \mathrm{O}_{3}[31,32]$.

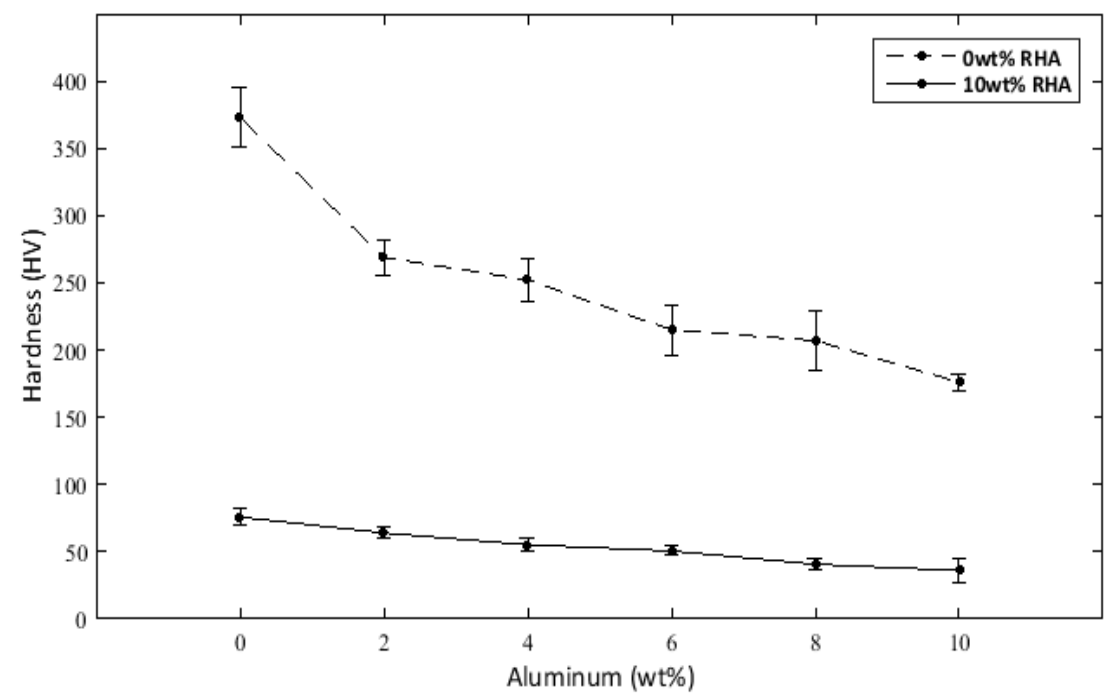

Figure 9. Reduction in hardness with the variation amounts of RHA and aluminum 
The results for the failure strength also exhibited a similar pattern to the hardness value. The failure strength-total porosity relationship can be related through mathematical function in Equation 4:

$$
\sigma_{f c}=C \sigma_{f s}(1-p)^{3 / 2}
$$

where, $\sigma_{f c}$ is tensile strength, $C$ a geometric constant characteristic of the unit cell shape, $\sigma_{f s}$ the webs strength and $p$ the porosity [33].

Failure strength is always inversely proportional to the total porosity. When embedded with $10 \mathrm{wt} . \%$ of RHA, the strength is reduced at the respective amount of aluminum (decrement between $22.56 \pm 13.22 \mathrm{MPa}$ to $42.28 \pm 17.06 \mathrm{MPa}$ ) due to the increase in total porosity which may influence crack propagation (Figure 10). The highest strength obtained is alumina without the addition of either RHA or aluminum $(55.62 \pm 17.92 \mathrm{MPa})$. This result is supported by Mohanta et al. who reported that the maximum strength value was obtained from the alumina without any materials embedded [9]. For 0 wt.\% RHA, by adding aluminum up to $8 \mathrm{wt} \%$, the strength was reduced from $55.62 \pm 17.92 \mathrm{MPa}$ to $31.76 \pm 14.11 \mathrm{MPa}$ (decrement of $23.86 \pm 3.81 \mathrm{MPa}$ ) and was improved at $10 \mathrm{wt} \% \mathrm{Al}$ (increment of $0.82 \pm 4.38 \mathrm{MPa}$ ). For $10 \mathrm{wt} \% \mathrm{RHA}$, the strength also reduced from $13.34 \pm 0.86 \mathrm{MPa}$ to $8.99 \pm 1.82 \mathrm{MPa}$ (decrement of $4.35 \pm 0.96 \mathrm{MPa}$ ) up to the addition of 6 wt $\% \mathrm{Al}$. Above this ratio (at $8 \mathrm{wt} . \%$ and $10 \mathrm{wt} . \% \mathrm{Al}$ ), the strength starts to increase to 9.20 $\pm 0.90 \mathrm{MPa}$ and 9.26 $\pm 1.65 \mathrm{MPa}$, respectively. Even though there has been an increment in strength, these values are still below the reference sample.

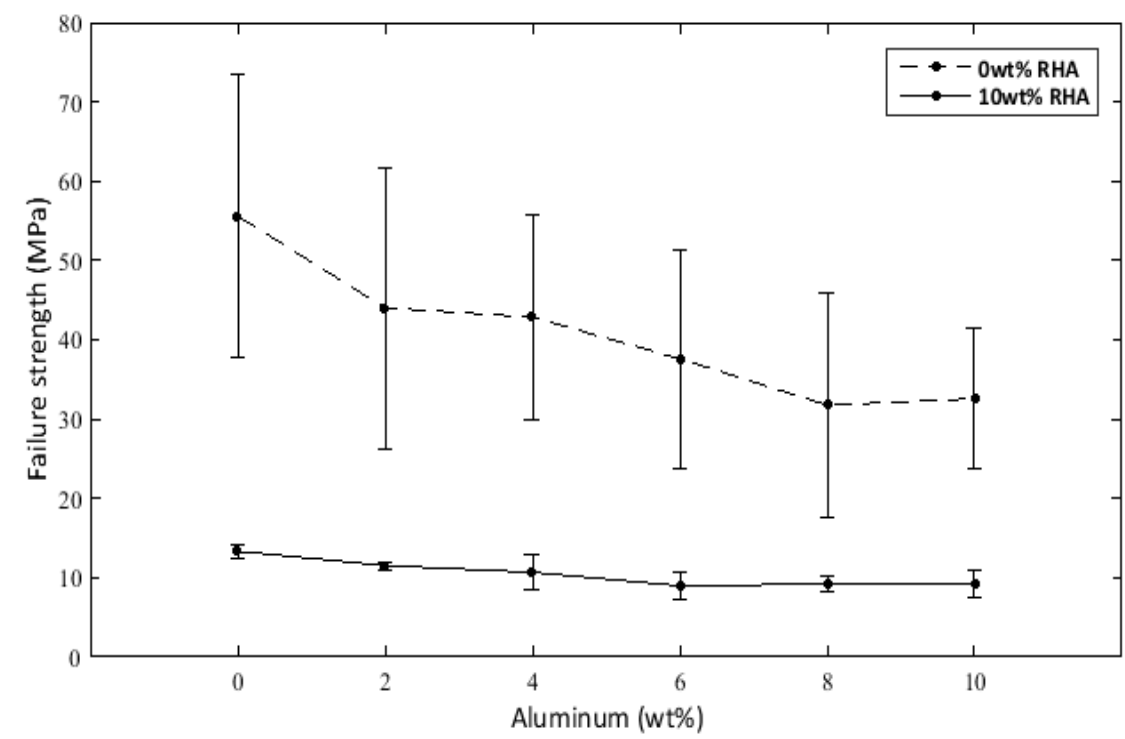

Figure 10. Reduction in failure strength with the variation amounts of RHA and aluminum

Theoretically, by adding aluminum, the hypothesis is to improve the strength due to the interfacial bonding between the alumina and the aluminum, which would prevent the propagation of the crack [12]. However, the results showed inverse behaviour. The images illustrated in Figure $6 \mathrm{~b}$ and $6 \mathrm{c}$ show that some of the aluminum melts during the sintering process, resulting in more pores. This may reduce the interfacial reaction between the alumina matrix and the aluminum, thus reducing its strength. 


\section{Conclusions}

This study had shown that the addition of RHA has a major impact on the properties of the pellets rather than the addition of aluminum. With the addition of $10 \mathrm{wt} \%$ RHA, the linear shrinkage, closed porosity, density, hardness and failure strength are reduced. The reduction was varied from $9.73 \pm 0.43 \%$ to $11.07 \pm 0.17 \%$ for linear shrinkage, $5.41 \pm 0.43 \%$ to $8.46 \pm 0.47 \%$ for closed porosity, $0.51 \pm 0.04 \mathrm{gcm}-3$ to $0.61 \pm 0.01 \mathrm{gcm}-3$ for density, $373.12 \pm 22.20 \mathrm{HV}$ to $75.78 \pm 6.11 \mathrm{HV}$ for hardness and $22.56 \pm 13.22 \mathrm{MPa}$ to $42.28 \pm 17.06$ MPa for failure strength. Meanwhile, the open and total porosity was increased from $10.82 \pm 0.36 \%$ to $19.46 \pm 0.77 \%$ and $12.03 \pm 1.14 \%$ to $15.23 \pm 0.37 \%$, respectively. Induced porosity is the prime concern in this study since the main applications are for filtration purposes.

\section{Acknowledgement}

The authors would like to express sincere gratitude to Universiti Putra Malaysia (UPM) for supporting the research and publications (Grant Putra). We would also like to thank AUN/SEED-Net for sponsoring the oral session participation in the Regional Conference on Materials \& ASEAN Microscopy Conference 2017.

\section{References}

[1] L. Lancaster, M.H. Lung, and D. Sujan, "Utilization of agro-industrial waste in metal matrix composites: Towards sustainability," In: Proceedings of World Academy of Science, Engineering and Technology, Vol. 73, pp. 1136-1144, 2013.

[2] A.M. Usman, A.O. Raji, and N.H. Waziri, "Characterisation of girei rice husk ash for silica potential," Journal of Environment Science Toxicology and Food Technology, Vol. 8, pp. 68-71, 2014.

[3] S.E. Salih, S.M. Al-Saffar, and S.M. Darkhan, "Effect of fly and dust ash additions on hardness and wear resistance of composite metal matrix (Al-Si-Mg)," Journal of Engineering and Technology, Vol. 29, No. 16, pp. 3345-3358, 2011.

[4] S. Kumagai, H. Ishizawa, Y. Aoki, and Y. Toida, "Molded micro- and mesoporous carbon/silica composite from rice husk and beet sugar," Chemical Engineering Journal, Vol. 156, No. 2, pp. 270-277, 2010.

[5] A.M. Usman, A. Raji, M.A. Hassan, and N.H. Waziri, "A comparative study on the properties of Al-7\% Si-Rice husk ash and Al-7\% Si-Bagasse ash composites produced by stir casting," International Journal of Engineering Science, Vol. 3, No. 8, pp. 1-7, 2014.

[6] K.K. Alaneme, and P.A. Olubambi, "Corrosion and wear behaviour of rice husk ashAlumina reinforced Al-Mg-Si alloy matrix hybrid composites," Journal of Material Research Technology, Vol. 2, No. 2, pp. 188-194, 2013.

[7] A.M. Usman, A. Raji, N.H. Waziri, and M.A. Hassan, "Production and characterisation of aluminium alloy-Bagasse ash composites," Journal of Mechanical and Civil Engineering, Vol. 11, No. 4, pp. 38-44, 2014.

[8] A.M. Usman, A. Raji, N.H. Waziri, and M.A. Hassan, "Aluminium alloy-rice husk ash composites production and analysis," Leonardo Electronic Journal of Practices and Technologies, Vol. 1, No. 13, pp. 84-98, 2014.

[9] K. Mohanta, A. Kumar, O. Parkash, and D. Kumar, "Low cost porous alumina with tailored microstructure and thermal conductivity prepared using rice husk and sucrose," Journal of American Ceramic Society, Vol. 97, pp. 1708-1719, 2014.

[10] T. Ohji, and M. Fukushima, "Macro-porous ceramics: Processing and properties," International Materials Review, Vol. 57, No. 2, pp. 115-131, 2012. 
[11] D.C. William, and G.R. David, Materials Science and Engineering: An Introduction, John Wiley and Sons, United States, 2011.

[12] V.S. Aigbodion, J.O. Agunsoye, V. Kalu, F. Asuke, and S. Ola, "Microstructure and mechanical properties of ceramic composites," Journal of Mineral and Material Characterisation Engineering, Vol. 9, No. 6, pp. 527-538, 2010.

[13] L. Hu, R. Benitez, S. Basu, I. Karaman, and M. Radovic, "Processing and characterization of porous Ti $2 \mathrm{AlC}$ with controlled porosity and pore size," Acta Materialla, Vol. 60, No. 18, pp. 6266-6277, 2012.

[14] P. Chindaprasirt, S. Rukzon, and V. Sirivivatnanom, "Resistance to chloride penetration of blended portland cement mortar containing palm oil fuel ash, rice hush ash and fly ash," Construction and Building Materials, Vol. 22, No. 5, pp. 932-938, 2008.

[15] G.A. Habeeb, and H.B. Mahmud, "Study on properties of rice husk ash and its use as cement replacement material," Materials Resources, Vol. 13, No. 2, pp. 185-190, 2010.

[16] P. Auerkari, Mechanical and Physical Properties of Engineering Alumina Ceramics, Technical Research Centre of Finland, Julkaisija - Utgivare - Publisher, Finland, 1996.

[17] N.C. Eric, The Oxidation of Aluminum at High Temperature Studied by Thermogravimetric Analysis and Differential Scanning Calorimetry, Sandia Report, Sandia National Laboratories, New Mexico, 2013.

[18] T. Luangvaranunt, C. Dhadsanadhep, J. Umeda, E. Nisaratanaporn, and K. Kondoh, "Aluminum-4 mass\% copper/alumina composites produced from aluminum copper and rice husk ash silica powders by powder forging," Material Transactions, Vol. 51, No. 4, pp. 756-761, 2010.

[19] S. Kumagai, and J. Sasaki, "Carbon/silica composite fabricated from rice husk by means of binderless hot-pressing," Bioresource Technology, Vol. 100, No. 13, pp. 3308-3315, 2009.

[20] C. Dhadsanadhep, T. Luangvaranunt, J. Umeda, and K. Kondoh, "Fabrication of $\mathrm{Al} / \mathrm{Al}_{2} \mathrm{O}_{3}$ composite by powder metallurgy method from aluminum and rice husk ash," Journal of Metals, Materials and Minerals, Vol. 18, No. 2, pp. 99-102, 2008.

[21] Aluminum Company of America, Alcoa Structural Handbook; A Design Manual for Aluminum, Pittsburgh, 1958.

[22] M. Munro, "Evaluated material properties for a sintered alpha-alumina," Journal of American Ceramic Society, Vol. 80, No. 8, pp. 1919-1928. 1997.

[23] G. Li, Y. Fan, Y. Zheng, and Y. Wu, "Preparation and properties of high toughness RBAO macroporous membrane support," Ceramic International, Vol. 36, pp. 20252031, 2010.

[24] S. Narayan, Rice Husk Ash, The Institute of Concrete Technology Newsletter, No. 55, 2004.

[25] C. San Marchi, M. Kouzeli, R. Rao, J. Lewis, and D. Dunand, "Alumina-aluminum interpenetrating-phase composites with three-dimensional periodic architecture," Scripta Materialia, Vol. 49, pp. 861-866, 2003.

[26] S. Jubair, R. Kamis, and F. Rassen, "Study of linear shrinkage for siliceous materials to meet insulating requirements," Iraqi Journal of Physics, Vol. 9, No. 16, pp. 73-78, 2011.

[27] M.M. Hossen, F.U.Z. Chowdhury, M.A. Gafur, A.A. Hakim, and S. Nasrin, "Investigation of mechanical properties of $\mathrm{Al} 2 \mathrm{O} 3-20 \mathrm{wt} \% \mathrm{ZrO} 2$ composites as a function of sintering temperature," European Science Journal, Vol. 10, No. 9, pp. 399-411, 2014.

[28] Q. Feng, H. Yamamichi, M. Shoya, and S. Sugita, "Study on the pozzolanic properties of rice husk ash by hydrochloric acid pretreatment," Cement and Concrete Research, Vol. 34, No. 3, pp. 521-526, 2004. 
[29] M. Nehdi, J. Duquette, and A. El Damatty, "Performance of rice husk ash produced using a new technology as a mineral admixture in concrete," Cement and Concrete Research, Vol. 33, pp. 1203-1210, 2003.

[30] N. Yalcin, and V. Sevinc, "Studies on silica obtained from rice husk," Ceramic International, Vol. 27, No. 2, pp. 219-224, 2001.

[31] F.H. Stott, L. Li, and J.F. Li, "Crystallographical analysis of surface layers of refractory ceramics formed using combined flame spray and simultaneous laser treatment," Journal of European Ceramic Society, Vol. 24, No. 10-11, pp. 3129-3138, 2004.

[32] Ferro Ceramic Grinding Inc., Data from: Ceramic Properties Tables Mullite and Ceramic Properties Tables Alumina 99.5 [dataset], Ceramic Properties [Online]. Available: http://www.ferroceramic.com [Accessed April 2019]

[33] Y.S. Han, J.B. Li, B. Chi, and Z.H. Wen, "The effect of sintering temperature on porous silica composite strength," Journal of Porous Materials, Vol. 10, No. 1, pp. 41-45, 2003. 